\title{
Skeletal muscle aging: influence of oxidative stress and physical exercise
}

\author{
Mariana Janini Gomes ${ }^{1}$, Paula Felippe Martinez², Luana Urbano Pagan¹, Ricardo \\ Luiz Damatto ${ }^{1}$, Marcelo Diacardia Mariano Cezar ${ }^{1}$, Aline Regina Ruiz Lima ${ }^{1}$, Katashi \\ Okoshi $^{1}$ and Marina Politi Okoshi ${ }^{1}$ \\ ${ }^{1}$ Botucatu Medical School, Internal Medicine Departament, Sao Paulo State University, UNESP, Botucatu, SP, Brazil \\ 2 School of Physical Therapy, Federal University of Mato Grosso do Sul, Campo Grande, Brazil \\ Correspondence to: Marina Politi Okoshi, email: mpoliti@fmb.unesp.br
}

Keywords: elderly, physical capacity, sarcopenia, training, treatment

Received: November 04, $2016 \quad$ Accepted: January 09, 2017

Published: January 15, 2017

\section{ABSTRACT}

Skeletal muscle abnormalities are responsible for significant disability in the elderly. Sarcopenia is the main alteration occurring during senescence and a key public health issue as it predicts frailty, poor quality of life, and mortality. Several factors such as reduced physical activity, hormonal changes, insulin resistance, genetic susceptibility, appetite loss, and nutritional deficiencies are involved in the physiopathology of muscle changes. Sarcopenia is characterized by structural, biochemical, molecular and functional muscle changes. An imbalance between anabolic and catabolic intracellular signaling pathways and an increase in oxidative stress both play important roles in muscle abnormalities. Currently, despite the discovery of new targets and development of new drugs, nonpharmacological therapies such as physical exercise and nutritional support are considered the basis for prevention and treatment of age-associated muscle abnormalities. There has been an increase in information on signaling pathways beneficially modulated by exercise; nonetheless, studies are needed to establish the best type, intensity, and frequency of exercise to prevent or treat age-induced skeletal muscle alterations.

\section{INTRODUCTION}

With improved life conditions in the population and the availability of treatments for various diseases, particularly infectious and cardiovascular diseases, life expectancy and consequently the number of elderly in the population has increased [1]. Worldwide the 60 years and over population is predicted to rise from 841 million in 2013 to more than 2 billion by 2050 [2]. Muscle tissue has a wide range of functions and skeletal muscle abnormalities are responsible for significant disability in the elderly [3]. Sarcopenia is an important alteration occurring during senescence and a key public health issue as it predicts frailty, poor quality of life, and mortality [4-7]. The prevalence of low muscle mass is estimated to be between 8 and $40 \%$ depending on the population studied and the methods used to identify sarcopenia [8]. It ranges from $15 \%$ at 65 years to $50 \%$ at 80 years
$[6,7,9]$. Although several factors can be involved, the physiopathology of muscle changes in healthy aging is not completely understood. Disruption of signaling networks involving systemic and skeletal muscle reactive oxygen species (ROS) has received increasing attention in recent decades [10]. Physical exercise is widely considered an important intervention for increasing longevity and promoting well-being and healthy aging.

In this review we first present the definition of sarcopenia. We then discuss the pathophysiological and molecular mechanisms underlying muscle changes during aging highlighting the role of oxidative stress. And finally, as strategies to prevent and treat age-associated muscle changes, we emphasize the role of physical exercise and introduce newer agents being developed. 


\section{DEFINITION OF SARCOPENIA}

Sarcopenia is characterized by age-associated progressive and generalized skeletal muscle mass and function loss occurring in the absence of underlying diseases. The definition of sarcopenia is still a matter of controversy and an evolving concept. In accordance with the European Working Group on Sarcopenia in Older People, sarcopenia diagnosis requires documentation of both low muscle mass and low muscle function (strength or performance) [11]. Low muscle mass was established as lean appendicular mass corrected for height squared of 2 or more standard deviations below the mean for healthy persons between 20 and 30 years of age from the same ethnic group $[12,13]$. By using this definition diagnosis depends on laboratory investigation. Although dual-energy $\mathrm{X}$-ray absorptiometry and bioelectrical impedance have been used to evaluate body composition and estimate total, lean and fat mass, computed tomography and magnetic resonance imaging are the gold standard for muscle mass assessment $[14,15]$. As these techniques are expensive, the approach recommended by the International Working Group on Sarcopenia and the Foundation for the National Institutes of Health Sarcopenia Project requires the presence of either low physical performance or muscle strength as indications to measure muscle mass $[9,16]$.

For clinical purposes, ranges of cut-points were proposed to evaluate physical performance, muscle strength, and appendicular lean mass. A gait speed lower than $0.8 \mathrm{~m} / \mathrm{s}$ to walk a set distance, such as $4 \mathrm{~m}$, at usual pace has been used to determine low physical performance $[11,12]$. Muscle strength can be evaluated by several different ways [11]. Grip strength is the most practical method in clinical settings and it correlates with lower limb physical performance measurements [17]. Grip strength cut-points have been proposed; they are 26-30 $\mathrm{kg}$ in men and $16-19 \mathrm{~kg}$ in women $[3,18]$. Interestingly, observations have shown that strength may predict the risk of disability and mortality better than muscle mass [19, 20]. Cut-points for skeletal muscle mass vary according to population, medical societies and the methods used to normalize muscle mass, whether height squared or body mass index [18]. An appendicular skeletal muscle mass $(\mathrm{kg})$ divided by height $(\mathrm{m})$ squared below $7.26 \mathrm{~kg} / \mathrm{m}^{2}$ in men and $5.45 \mathrm{~kg} / \mathrm{m}^{2}$ in women has been used to diagnose sarcopenia $[16,21]$.

Sarcopenia should be differentiated from muscle loss associated with chronic disease, which is preferably called muscle wasting. Distinct syndromes with prominent muscle wasting include cachexia, frailty, and sarcopenic obesity $[14,22]$. Cachexia is characterized by body weight, fat, and muscle loss due to an underlying illness [4]. Frailty, also associated with medical comorbidities, has been empirically characterized by weight loss, slowness, exhaustion, low physical activity, and weakness. Three of these frailty indicators are required to define the full frailty syndrome [23]. Sarcopenic obesity is the coexistence of obesity and sarcopenia. Lipid infiltration in muscle tissues exacerbates sarcopenia by preventing amino acids incorporation and protein synthesis [24, 25].

\section{AGING-ASSOCIATEDSKELETALMUSCLE ALTERATIONS}

The main alteration associated with aging is muscle atrophy. Progressive muscle mass loss starts at approximately the age of 40 years; it is estimated at about $8 \%$ per decade until the age of 70 years and then it increases to $15 \%$ per decade [6]. Reduction in muscle mass is combined with an increase in body fat mass; consequently, body weight usually remains unchanged.

Several underlying structural and biochemical changes in muscle have been described in the elderly. Muscle cross-sectional area can be up to $30 \%$ less at 70 years than at 20 years old and is associated with an accumulation of fat within muscle [26, 27]. A shift in muscle fiber composition occurs in advancing age with a decrease in large fast-twitch glycolytic (Type II) fiber [9]. Changes in motor neurons have also been observed; with ageing, the number and activity of motor units are decreased impairing motor control $[28,29]$. Alterations in the type of fibers may occur when type II myofibers are re-innervated by type I motor neurons [28]. However, whether this motor unit change is a cause of sarcopenia or a compensatory adaptive response to sarcopenia is unresolved [12].

As a consequence of structural and biochemical changes, muscle strength and functional capacity are reduced in the sarcopenic elderly [30]. The Health and Body Composition Study including 1880 older subjects showed a strong association between muscle mass and strength [31]. Leg strength decreases $10-15 \%$ per decade until 70 years of age, and then it declines $25 \%$ to $40 \%$ by decade [6]. Muscle strength is approximately $20-40 \%$ lower at 70 years than in young adults [27]. Reduction in muscle function is an important issue in clinical settings as it is independently associated with increased risk of falls, disability, and mortality in the elderly [32].

\section{ETIOLOGY AND INTRACELLULAR PATHWAYS INVOLVED IN AGING- ASSOCIATED MUSCLE CHANGES}

Muscle loss is a multifactorial and not completely understood condition which occurs in the elderly and several systemic diseases [33, 35]. Although its main causative agents include reduced physical activity [36, 37], hormonal changes [38], insulin resistance [39, 40], genetic susceptibility [41], appetite loss and nutritional deficiencies $[42,43]$, their contribution to the normal aging process has not been fully determined. 
Physiological maintenance of skeletal muscle mass depends on a delicate balance between anabolic and catabolic factors. Muscle loss results from a disproportionate decrease in muscle protein synthesis and/or an increase in protein breakdown (Figure 1) [9]. There is substantial evidence that anabolic drive is reduced in ageing [12]. An important anabolic pathway inducing protein synthesis involves activation of the phosphatidylinositol 3-kinase (PI3K)/serine threonine kinase (Akt), which stimulates mammalian target of rapamycin (mTOR) [44]. Most anabolic stimuli, such as: insulin and insulin-like growth factor 1 (IGF-1), exercise, and testosterone, upregulate this pathway [45]. As aging is associated with a sedentary lifestyle, IGF-1 and insulin resistance, and lower testosterone levels, this pathway is inhibited and muscle protein synthesis is blunted [4]. A vicious cycle can be observed in aging as muscle loss impairs physical capacity and immobility reduces muscle mass [12]. Furthermore, testosterone can also stimulate myoblasts and satellite cells [46]; and IGF-1 stimulates satellite cell proliferation [47, 48] and inhibits protein degradation $[49,50]$. All these mechanisms which act in myocyte repair and muscle mass preservation are blunted in aging.

The role of increased protein catabolism on muscle changes is less understood [51]. The main proteolytic pathways can be found in skeletal muscle: lysosomal, $\mathrm{Ca}^{2+}$ dependent, caspase dependent, and ubiquitin-proteasome dependent pathways [52]. The ubiquitin-proteasome system is one of the most important pathways responsible for intracellular degradation of striated muscle proteins [53-55]. However, its role remains controversial during aging; recent data suggests that protein degradation is more likely mediated by the $\mathrm{Ca}^{2+}$ dependent calpain and autophagy pathways than the ubiquitin-proteasome system $[50,56]$. Under physiological conditions, autophagic

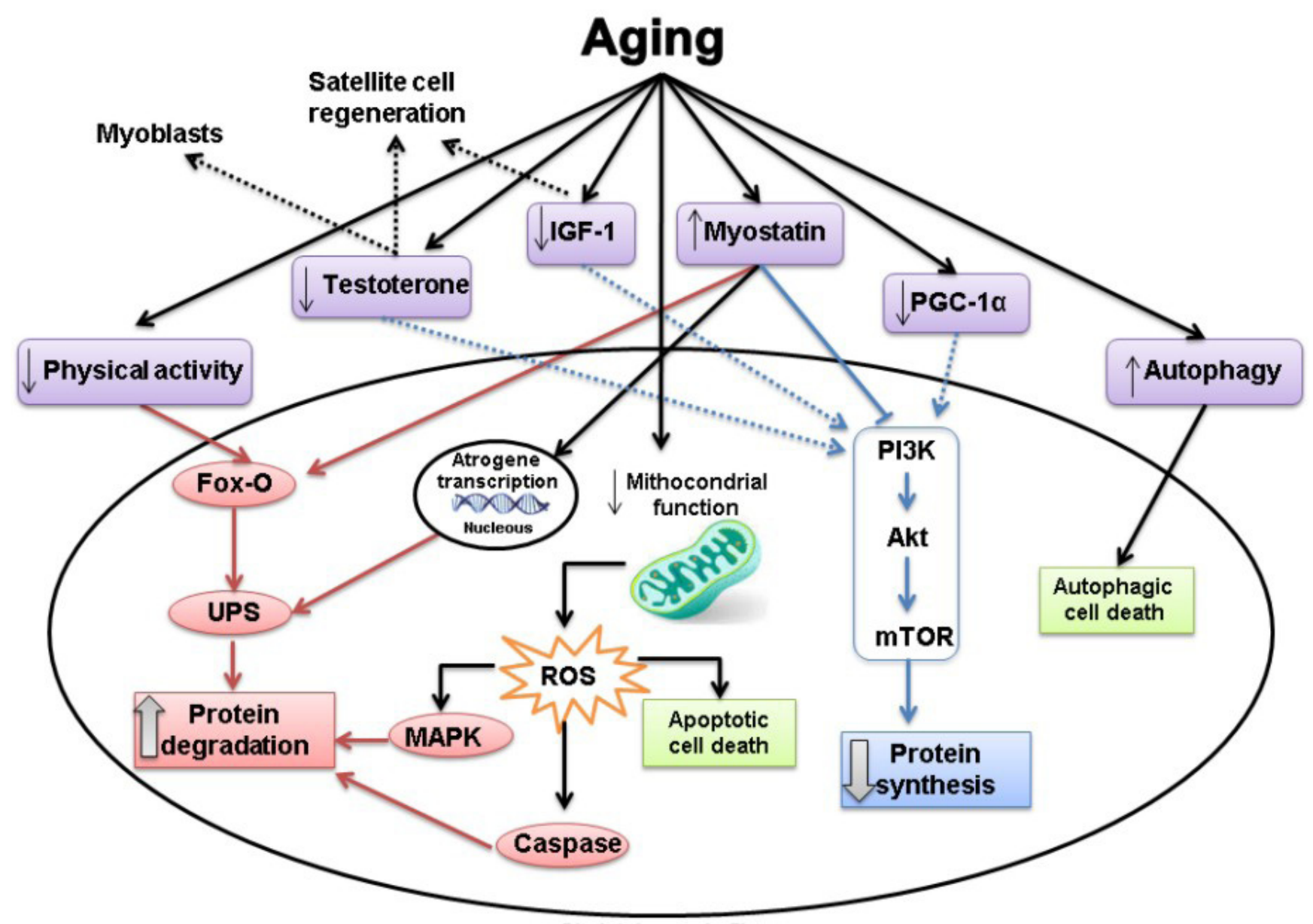

Skeletal muscle fiber

Figure 1: The effects of aging on the signalling pathways associated with protein synthesis and protein degradation. Red: catabolic pathways. Blue: anabolic pathways. Dash lines: inhibition. Dotted lines: no stimulation. The main alteration associated with aging is muscle atrophy. Muscle loss results from a disproportionate decrease in muscle protein synthesis and/or an increase in protein breakdown. Protein synthesis and degradation are regulated by several different stimuli, which activate multiple signaling pathways. See the main text for further details. 
processes are closely regulated; autophagy inhibition leads to intracellular garbage accumulation, while its excessive activation is associated with autophagic cell death and loss of muscle mass [57]. The PI-3K/Akt/mTOR pathway, as well as stimulating protein synthesis, inhibits protein degradation [4]. PI-3K/Akt inhibits forkhead box transcription factor $\mathrm{O}$ (Fox-O), a potent inductor of the ubiquitin-proteasome system, and mTOR decreases caspases activity. Furthermore, physical inactivity stimulates Fox-O, which can also inhibit the mTOR pathway [4]. Also the reduction in number and activity of lower motor neurons contribute to inactivity and muscle breakdown [29].

Satellite cells are a major source of muscle regeneration; however, it is unclear whether a decrease in their number or regenerative capacity is involved in aging muscle changes $[50,58]$. Another pathway which may be involved in muscle atrophy is myostatin, a member of the transforming growth factor- $\beta$ family. Myostatin is secreted by cardiac and skeletal muscle cells and acts locally by negatively modulating skeletal muscle mass. Myostatin inhibits the Akt/mTOR pathway, activates Fox-O, and decreases satellite cells number and regeneration $[45,50]$. Despite all these effects, the role of myostatin on aging and different muscle wasting conditions is not completely clear [4, 59-61].

Mitochondria integrate several cell signals including energy supply, ROS generation, and apoptosis. A decrease in mitochondrial content and function was observed during ageing and may contribute to reduced mitochondrial bioenergetics and increased mitochondrial-derived ROS production and apoptotic cell death [56, 62-65]. Apoptosis decreases muscle size by reducing fiber number and decreasing the nuclear-to-cytoplasm ratio by targeted myonuclei removal [29]. Mitophagy, the removal and degradation of dysfunctional portions of mitochondria, is also changed during aging $[56,66]$. Peroxisome proliferator-activated receptor gamma coactivator 1-alpha (PGC-1 $\alpha$ ) is a key regulator of mitochondrial biogenesis in skeletal muscle. Recent data suggested that a reduction in PGC- $1 \alpha$ signaling is associated with decreased Akt and mTOR expression in ageing [67]. Furthermore, overexpression of PGC- $1 \alpha$ in aged mice attenuated mitochondrial impairment, apoptosis, autophagy, proteasome activity, and muscle loss [67]. Mitochondrial changes are therefore considered to greatly contribute to age-associated muscle alterations [29, 50, 56, 68].

More recently, the role of iron on muscle changes has attracted great interest. Iron deficiency has been linked to several alterations such as decreased physical capacity and muscle mass; altered oxidative-to-glycolytic fiber ratio; reduced myoglobin pool; decreased mitochondria and mitochondrial cristae density; and reduced oxidative metabolism with increased glycolytic activity [69]. Despite this information suggesting iron deficiency plays a role in impairing physical capacity, iron status has been poorly addressed in age-associated muscle changes.

Finally, inflammation is not considered an important factor causing muscle loss in healthy ageing [15]. Although increased interleukin-6 levels can occur in advancing age [67], and elevated tumor necrosis factor alpha $(\mathrm{TNF}-\alpha)$ in elderly individuals has been associated with reduced muscle mass and strength [6], it is not clear whether inflammatory activation is due to ageing alone or underlying comorbidities. Furthermore, inflammatory pathways involving $\mathrm{NF}-\kappa \mathrm{B}$ are typically not activated in sarcopenia [4].

\section{REACTIVE OXYGEN SPECIES AND SKELETAL MUSCLE AGEING}

Oxidative stress is characterized by increased levels of ROS and/or reactive nitrogen species. It can be caused by decreased antioxidant capacity due to low concentrations of antioxidants and impaired antioxidant enzymes activity, and/or by increased ROS production [70]. At physiological concentrations, ROS play essential roles in redox signaling and cell survival by activating or inhibiting enzymes such as mitogen-activated protein kinase (MAPK), phosphatases, and gene-dependent cascades [30]. However, high ROS levels induce alterations or damage to DNA, proteins, and lipids, and can stimulate apoptotic cell death $[50,71]$.

Skeletal muscles consume large quantities of oxygen and can generate a great amount of ROS. ROS are mainly generated in mitochondria during normal respiration as a by-product of oxidative phosphorylation [29, 71]. They can also be produced in cytosol and membranes in response to different stimuli including growth factors and inflammatory cytokines [71-73]. Several enzymes participate in ROS generation, including xanthine oxidase, nicotinamide adenine dinucleotide phosphate (NADPH) oxidase, and nitric oxide synthase [74]. Skeletal muscle also generates reactive nitrogen species (RNS) [75]. The ROS/RNS-induced modifications include nitration, nitrosylation, carbonylation, and glycation [30]. Under physiological conditions, oxidative stress is neutralized by the antioxidant system, which includes endogenous and exogenous molecules. The main enzymatic defenses are superoxide dismutase, catalase, and glutathione peroxidase [71]. These enzymes can be modified by exercise, nutrition, and aging [76]. Exogenous antioxidants mainly include vitamins (e.g., vitamin E, vitamin C) and minerals (zinc, copper, iron) [30]. The antioxidants maintain muscle redox status and attenuate ROS-induced intracellular changes [30].

Due to the increased oxidative stress levels observed in aged muscle, ROS accumulation has been suggested as playing a role in muscle changes and sarcopenia. The first free-radical theory of aging was proposed by Harman in 1956 [77], who hypothesized that endogenously generated reactive oxidants cause cumulative oxidative damage to 
macromolecules resulting in the aging phenotype. In aging, oxidant production from several sources is increased, antioxidant enzymes are decreased, and the adaptive response to oxidative stress is reduced. Increases in ROS and RNS production are mainly due to mitochondrial dysfunction caused by age-related mitochondrial DNA mutations, deletions, and damage. Extensive damage to mitochondrial DNA and impaired DNA repair mechanisms in skeletal muscle have been observed with advancing age [29, 78, 79]. Furthermore, the impaired ability of muscle cells to remove dysfunctional mitochondria can contribute to enhanced ROS production [56]. These increased ROS levels cause progressive damage to mitochondrial DNA, thus creating a vicious cycle [29, 80, 81].

As previously reported, faster age-induced decline in Type II fibers can at least be partially attributable to a greater oxidative injury and apoptosis, as this type of fiber has lower mitochondrial content and is more susceptible to atrophy than the Type I fibers with a high mitochondrial content $[82,83]$. Increased ROS production also activates the ubiquitin-proteasome system and muscle proteases (i.e., caspases, calpains) leading to protein breakdown [30]. Furthermore, repair systems, such as the proteasomal degradation of damaged proteins, are impaired in aging $[30,84]$.

ROS and RNS accumulation is also associated with intracellular functional changes in fiber activation at the neuromuscular junction, excitation-contraction coupling, and at cross-bridge cycling within the myofibrillar apparatus [30]. Intrinsic changes in the excitationcontraction process can explain the fact that strength deficit can be more rapid than the concomitant reduction in muscle size in elderly individuals [30].

\section{PREVENTION AND TREATMENT OF AGEING-ASSOCIATED SKELETAL MUSCLE CHANGES}

Despite extensive studies on the molecular pathways involved in age-associated skeletal muscle changes, it has been difficult to develop specific therapies for their prevention and treatment. Different options have been described, mostly evaluated in experimental settings or small clinical trials. Currently, nonpharmacological therapies such as physical exercise and nutritional support are considered the basis for prevention and treatment of age-associated muscle abnormalities [9].

\section{PHYSICAL EXERCISE}

Exercise is the most effective intervention in preventing and treating skeletal muscle changes and sarcopenia in older individuals. Exercise training not only attenuates muscle loss but increases muscle mass and strength, and improves functional capacity and survival
[15, 57, 85-89]. However, the molecular mechanisms and signaling pathways involved in exercise benefits are not completely clear.

Anabolic and catabolic muscle pathways are strongly influenced by physical exercise. Regular training improves muscle mass and strength by increasing protein synthesis, number of myofibrils, and fiber cross-sectional area [90]. Exercise increases IGF-1 levels with the subsequent activation of mTOR to induce protein synthesis; mTOR may also be activated by muscle mechanical loading [50, 85]. Furthermore, exercise increases myofibrillar protein through satellite cell activation, and decreases muscle fat infiltration [85]. Besides stimulating muscular anabolism, exercise inhibits protein degradation, an effect probably mediated by the lower levels of oxidative stress following training (see below) [50]. The intensity of autophagic modulation by exercise depends on fiber type and training duration and intensity [57]. Other mediators of muscle loss that exercise may target in ageing are myostatin and Fox-O, which are reduced by aerobic training [91]. Reduced myostatin signaling represses atrogene transcription and consequently protein degradation [50].

Physical training also modulates other muscle cell organelles [92]. Mitochondria are strongly influenced by exercise, which prevents a decrease in their content and function during aging $[56,62]$. In fact, the level of physical activity is one of the most important determinants of mitochondrial function in aging muscle [56].

In 1982 Davies et al. [93] observed increased muscle ROS generation in exercised rats. It was later demonstrated that a single bout of exercise exceeding a certain intensity or duration increases ROS production from the mitochondrial respiratory chain or other oxidases and leads to oxidative damage to lipids, proteins, and DNA [94]. However, regular exercise increases ROS formation to a level that may cause significant but tolerable damage, which in turn, can induce beneficial adaptations by upregulating cellular antioxidant systems and stimulating oxidative damage repair systems [95-100]. In fact, a clinical trial showed that the effects of exercise mediated by a transient increase in ROS production leading to enhanced insulin sensitivity were prevented by antioxidant supplementation with vitamin C or vitamin E [101]. These results suggest that acute ROS production in healthy individuals is required for skeletal muscle adaption to exercise [75]. Thus, contrary to what occurs after acute bouts of exercise, chronic exercise is associated with decreased levels of oxidative stress markers and increased enzymatic and non-enzymatic antioxidant capacity in young, middle-aged, and elderly individuals [29, 102106]. Muscle biopsies showed reduced oxidative stress and increased catalase expression in lifelong trained older adults compared with their untrained counterparts $[50,107]$. Increases in antioxidant enzymes have been associated with improvements in ageing skeletal muscle changes [108]. For example, overexpression of anti- 
oxidant enzyme $\mathrm{Cu}^{2+}, \mathrm{Zn}^{2+}$-superoxide dismutase in mice prevented age-related muscle impairment [108].

PGC- $1 \alpha$ is a central regulator of exercise-induced mitochondrial adaptations and metabolic reprogramming. After exercise, its expression is activated by kinases including MAPK and adenosine monophosphate-activated protein kinase (AMPK), which are stimulated by ROS [29]. It was recently observed that PGC- $1 \alpha$ level was enhanced following low intensity, long duration acute swimming and was associated with reduced apoptosis in mice skeletal muscle [109]. Furthermore, increased PGC$1 \alpha$ expression in ageing mice was associated with lower oxidative stress, inflammation, apoptosis, autophagy, and proteasome activation; higher mitochondrial biogenesis; and prolonged survival [67]. Exercise also increases PGC$1 \alpha 4$ isoform, which induces protein synthesis via the IGF1 pathway and represses myostatin [50].

Improved adenosine triphosphate (ATP) synthesis, oxidative phosphorylation, and $\mathrm{Ca}^{2+}$ homeostasis were also observed in elderly skeletal muscles after training $[29,57]$. Resistance exercise appears to decrease TNF- $\alpha$ expression in aged skeletal muscle, which may attenuate age-associated muscle changes [110]. Finally, exercise induced favorable skeletal muscle angiogenesis and improved endothelial function in elderly individuals [111, 112].

Despite all the information on exercise modulating signaling pathways, there is little knowledge on the best type, intensity, and frequency of exercise to prevent or treat age-induced muscle loss [113]. Furthermore, not only changes in limb musculature but changes in inspiratory muscles might account for lower exercise capacity in the elderly [12]. Exercise intensity also influences muscle changes. Decreased basal hydrogen peroxide $\left(\mathrm{H}_{2} \mathrm{O}_{2}\right)$ production in muscle tissue was observed after 16 weeks training at $65 \%$ of maximal oxygen uptake $\left(\mathrm{VO}_{2 \max }\right)[114]$ and an increase in muscle antioxidant defense was found after 8 weeks of endurance training in older individuals [115]. Although recent publications have suggested that regular high intensity physical activity can be better than moderate intensity in healthy and unhealthy older individuals [116-118], greater physical fitness observed at high intensity exercise increased lipid peroxidation damage more than at a low physical fitness level [117]. Currently, data from literature suggest that optimal aerobic training for improving oxidative/antioxidant balance can be achieved with intensities between the two ventilatory thresholds $\left(50-80 \%\right.$ of $\left.\mathrm{VO}_{2} \max \right)$ at a frequency of $2-3$ sessions per week [71].

Concerning resistance training, it was recently observed that a 12-week resistance training with a frequency of 2 days per week improved muscular strength and oxidative stress in older women and 12 weeks detraining did not completely reverse the changes [119]. Researchers recommend that training protocols should contain sufficient volume for each muscle group
(3-5 sets, 10 repetitions) with intensities between 50 and $80 \%$ of one repetition maximum [71]. Although current data support the use of both endurance and resistance training in older adults with respect to superior beneficial mitochondrial adaptations and functional outcomes than isolated endurance training, more research is needed to confirm this [29].

\section{NUTRITION}

Nutritional status should be carefully evaluated to identify and prevent protein and micronutrient deficits. All the factors important for muscle function should be addressed. Vitamin D deficiency is common and affects all ages and both sexes. As evidence suggests that vitamin $\mathrm{D}$ is important for muscle function, maintaining adequate vitamin D status may be considered in preventing and treating age-associated muscle changes. Thirteen weeks of oral vitamin D supplementation and leucine-enriched whey protein improved muscle mass and lower-extremity function in older sarcopenic individuals [120]. Currently, prospective studies are underway to better define the role of vitamin D on skeletal muscles [121, 122].

As previously reported, iron participates in skeletal muscle function [69]. Although this issue has been poorly addressed in age-associated muscle changes, research on diseases such as heart failure and chronic obstructive pulmonary disease have suggested that iron deficiency may impair physical capacity. Therefore, iron status should be evaluated when muscle dysfunction is present without an apparent reason and iron deficiency treatment should be viewed as an emerging therapeutic target [69].

Ingestion of an adequate amount of high-quality protein in combination with physical activity appears a promising strategy to prevent or treat sarcopenia [123]. However, results of interventions are inconsistent and it is unknown whether specific nutritional therapy alone can reverse muscle loss [12]. Therefore, randomized studies analyzing the effects of nutrition interventions are needed to establish specific recommendations on nutritional support [124]. Guidelines for the nutrition and nutritional support of elderly individuals have been published [125, 126] and will not be discussed here.

\section{PERSPECTIVES FOR FUTURE}

Potential contenders for preventing or treating ageinduced skeletal muscle changes have been described. Candidate drugs include myostatin antagonists, follistatin, activin receptor antagonists, ghrelin agonists, selective androgen receptor molecules, megestrol acetate, beta antagonists, espindolol, formoterol, angiotensin converting enzyme inhibitors, and fast skeletal muscle troponin activators $[12,18,127]$.

The value of testosterone replacement therapy for older men is currently under intense debate. Ageing is 
accompanied by reduced protein synthesis and transporter. It was recently shown that these changes may be reversed by dihydrotestosterone treatment [128]. Other studies have also suggested that testosterone increases muscle mass and power [127, 129]. Growth hormone, a modulator of muscle growth and differentiation, has been evaluated to preserve skeletal muscle mass and myocardial metabolism under different conditions [130, 131]. Growth hormone administration to healthy older men increased lean body mass without changing muscle functional parameters [132]. However, due to testosterone and growth hormone potentially limiting side effects $[124,125,132]$, research is needed before recommending hormonal supplementation in clinical practice.

Anti-myostatin antibodies have been extensively investigated under different clinical conditions associated with muscle loss. Treatment of elderly mice with an antimyostatin antibody (ATA 842) for 4 weeks increased muscle mass and strength and improved insulin-stimulated muscle glucose uptake [133]. In a clinical setting, a multicenter study showed that administration of myostatin antibody LY2495655 to subjects 75 years or older who had fallen in the past year increased lean mass and might improve functional muscle power [134]. Additional studies are needed to confirm these results.

Recently, myocardial metabolic modulator trimetazidine (TMZ) was evaluated in skeletal muscle. Trimetazidine prevented hypotrophy of skeletal muscle cells in culture with different hypotrophic agents [135] and improved skeletal muscle strength of elderly mice [136]. Intraperitoneal administration of the newly developed mitochondria-targeted ROS and electron scavenger, XJB-5-131, reversed age-related mitochondrial function alterations and improved contractile properties in skeletal muscle [137]. Oxandrolone improved body composition adaptations to 12 weeks exercise in older women without however increasing muscle function or functional performance beyond that of exercise alone [138]. The benefits of low level laser therapy as an intervention to enhance muscle performance in the elderly is under investigation [139]. Collagen peptide supplementation combined with resistance training increased fat free mass and muscle strength in elderly sarcopenic men compared with training alone [140]. Reduction in histone deacetylase activity had a protective effect in models of neurogenic muscle atrophy [141]. As sarcopenia is associated with a reduction in motor neuron innervation, the potential for histone deacetylase inhibitor butyrate to modulate age-related muscle loss was investigated in older mice. Butyrate treatment starting at 16 months of age showed promising results by attenuating muscle atrophy [142].

Finally, it should be emphasized that a comprehensive geriatric assessment involving a multidisciplinary team enables medical staff to optimize the treatment of older individuals with skeletal muscle changes [143].
In summary, skeletal muscle changes are prevalent in the geriatric population and are associated with impaired outcomes. The main alteration is sarcopenia, which is characterized by structural, biochemical, molecular and functional changes. Muscle loss is a multifactorial condition with an imbalance in anabolic and catabolic intracellular pathways. Oxidative stress seems to play an important role in age-induced skeletal muscle abnormalities. Currently, despite the development of new agents, nonpharmacological therapies such as physical exercise and nutritional support are considered the basis for prevention and treatment of age-associated muscle abnormalities.

\section{Abbreviations}

Akt, serine threonine kinase; AMPK, adenosine monophosphate-activated protein kinase; ATP, adenosine triphosphate; Fox-O, inhibits forkhead box transcription factor $\mathrm{O} ; \mathrm{H}_{2} \mathrm{O}_{2}$, hydrogen peroxide; IGF1 , insulin growth factor 1; MAPK, mitogen-activated protein kinase; mTOR, mammalian target of rapamycin; NADPH, nicotinamide adenine dinucleotide phosphate; $\mathrm{NF}-\kappa \mathrm{B}$, nuclear factor kappa B; PGC-1 $\alpha$, peroxisome proliferator-activated receptor gamma coactivator 1-alpha; PI3K, phosphatidylinositol 3-kinase; RNS, reactive nitrogen species; ROS, reactive oxygen species; TMZ, trimetazidine; TNF- $\alpha$, tumor necrosis factor alpha; $\mathrm{VO}_{2}$ max, maximal oxygen uptake.

\section{ACKNOWLEDGMENTS} editing.

We are grateful to Colin Edward Knaggs for English

\section{CONFLICTS OF INTEREST}

None of the authors have any competing interests in the manuscript.

\section{FUNDING}

Financial support was provided by CAPES, CNPq (306770/2015-6 and 308674/2015-4), FAPESP (2014/21972-3; 2015/17539-5 and 2014/23592-3), and PROPe, UNESP.

\section{Author contributions}

Conception and design of the research: Gomes MJ, Okoshi MP; acquisition of data: Pagan LU, Damatto RL, Cezar MDM, Lima ARR; analysis and interpretation of the data: Gomes MJ, Martinez PF, Okoshi MP; obtaining financing and critical revision of the manuscript for 
intellectual content: Okoshi K, Okoshi MP; writing of the manuscript: Gomes MJ, Okoshi MP. All authors have read and approved the publication of this manuscript.

\section{REFERENCES}

1. Suzman R, Beard JR, Boerma T, Chatterjiemail S. Health in an ageing world. What do we know? Lancet. 2015; 385: 484-6.

2. Chatterji S, Byles J, Cutler D, Seeman T, Verdes E. Health, functioning and disability in older adults. Current status and future implications. Lancet. 2015; 385: 563-75.

3. Dodds R, Sayer AA. Sarcopenia. Arq Bras Endocrinol Metab. 2014; 58: 464-9.

4. Ali S, Garcia JM. Sarcopenia, cachexia and aging: Diagnosis, mechanisms and therapeutic options. A minireview. Gerontology. 2014; 60: 294-305.

5. Wolfe RR. The underappreciated role of muscle in health and disease. Am J Clin Nutr. 2006; 84: 475-82.

6. Kim TN, Choi KM. Sarcopenia: Definition, epidemiology, and pathophysiology. J Bone Metab. 2013; 20: 1-10.

7. Yu SCY, Khow KSF, Jadczak AD, Visvanathan R. Clinical screening tools for sarcopenia and its management. Curr Gerontol Geriatr Res. 2016; 2016: ID 5978523.

8. Abellan van Kan G. Epidemiology and consequences of sarcopenia. J Nutr Health Aging. 2009; 13: 708-12.

9. Fielding RA, Vellas B, Evans WJ, Bhasin S, Morley JE, Newman AB, Abellan van Kan G, Andrieu S, Bauer J, Breuille D, Cederholm T, Chandler J, De Meynard C, et al. Sarcopenia: an undiagnosed condition in older adults. Current consensus definition: prevalence, etiology, and consequences. International Working Group on Sarcopenia. J Am Med Dir Assoc. 2011; 12: 249-56.

10. Viña J, Borras C, Abdelaziz KM, Garcia-Valles R, GomezCabrera MC. The free radical theory of aging revisited: the cell signaling disruption theory of aging. Antioxid Redox Signal. 2013; 19: 779-87.

11. Cruz-Jentoft AJ, Baeyens JP, Bauer JM, Boirie Y, Cederholm T, Landi F, Martin FC, Michel JP, Rolland Y, Schneider SM, Topinková E, Vandewoude M, Zamboni $\mathrm{M}$, et al. European Working Group on Sarcopenia in Older People. Sarcopenia: European consensus on definition and diagnosis: Report of the European Working Group on Sarcopenia in Older People. Age Ageing. 2010; 39: 412-23.

12. Ebner N, Sliziuk V, Scherbakov N, Sandek A. Muscle wasting in ageing and chronic illness. ESC Heart Failure. 2015; 2: 58-68.

13. Morley JE, Abbatecola AM, Argiles JM, Baracos V, Bauer J, Bhasin S, Cederholm T, Coats AJ, Cummings SR, Evans WJ, Fearon K, Ferrucci L, Fielding RA, et al. The Society on Sarcopenia, Cachexia and Wasting Disorders Trialist Workshop. Sarcopenia with limited mobility: an International Consensus. J Am Med Dir Assoc. 2011; 12: 403-9.
14. Fulster S, Tacke M, Sandek A, Ebner N, Tschope C, Doehner W, Anker SD, von Haehling S. Muscle wasting in patients with chronic heart failure: results from the studies investigating comorbidities aggravating heart failure (SICA-HF). Eur Heart J. 2013; 34: 512-9.

15. Ebner N, Elsner S, Springer J, von Haehling S. Molecular mechanisms and treatment targets of muscle wasting and cachexia in heart failure: an overview. Curr Opin Support Palliat Care. 2014; 8: 15-24.

16. Woo J, Leung J. Anthropometric cut points for definition of sarcopenia based on incident mobility and physical limitation in older chinese people. J Gerontol A Biol Sci Med Sci. 2016; 71: 935-40.

17. Visser M, Deeg DJ, Lips P, Harris TB, Bouter LM. Skeletal muscle mass and muscle strength in relation to lowerextremity performance in older men and women. J Am Geriatr Soc. 2000; 48: 381-6.

18. McLean RR, Kiel DP. Developing consensus criteria for sarcopenia: an update. J Bone Miner Res. 2015; 30: 588-92.

19. Newman AB, Kupelian V, Visser M, Simonsick EM, Goodpaster BH, Kritchevsky SB, Tylavsky FA, Rubin SM, Harris TB. Strength, but not muscle mass, is associated with mortality in the health, aging and body composition study cohort. J Gerontol A Biol Sci Med Sci. 2006; 61: 72-7.

20. Manini TM, Clark BC. Dynapenia and aging: an update. J Gerontol A Biol Sci Med Sci. 2012; 67: 28-40.

21. Dodds R, Sayer AA. Sarcopenia and frailty: new challenges for clinical practice. Clin Med. 2015; 15: s88-91.

22. Heymsfield SB, Gonzalez MC, Lu J, Jia G, Zheng J. Skeletal muscle mass and quality: evolution of modern measurement concepts in the context of sarcopenia. Proc Nutr Soc. 2015; 74: 355-66.

23. Suemoto CK. Towards a unified and standardized definition of the frailty phenotype. Sao Paulo Med J. 2016.

24. Moreira MA, Zunzunegui MV, Vafaei A, da Câmara SM, Oliveira TS, Maciel ÁC. Sarcopenic obesity and physical performance in middle aged women: a cross-sectional study in Northeast Brazil. BMC Public Health. 2016; 16: 43.

25. Chang CI, Huang KC, Chan DC, Wu CH, Lin CC, Hsiung CA, Hsu CC, Chen CY. The impacts of sarcopenia and obesity on physical performance in the elderly. Obes Res Clin Pract. 2015; 9: 256-65.

26. Muscaritoli M, Anker SD, Argilés J, Aversa Z, Bauer JM, Biolo G, Boirie Y, Bosaeus I, Cederholm T, Costelli P, Fearon KC, Laviano A, Maggio M, et al. Consensus definition of sarcopenia, cachexia and pre-cachexia: joint document elaborated by Special Interest Groups (SIG) "cachexia-anorexia in chronic wasting diseases" and "nutrition in geriatrics". Clin Nutr. 2010; 29: 154-59.

27. Porter MM, Vandervoort AA, Lexell J. Aging of human muscle: structure, function and adaptability. Scand J Med Sci Sports. 1995; 5: 129-42.

28. Roman D, Mahoney K, Mohamadi A. Sarcopenia: what's in a name? J Am Med Dir Assoc. 2013; 14: 80-2. 
29. Joseph AM, Adhihetty PJ, Leeuwenburgh C. Beneficial effects of exercise on age-related mitochondrial dysfunction and oxidative stress in skeletal muscle. J Physiol. 2016; 594: 5105-23.

30. Baumann CW, Kwak D, Liu H, Thompson LV. Ageinduced oxidative stress: How does it influence skeletal muscle quantity and quality? J Appl Physiol. 2016; 121: 1047-52.

31. Goodpaster BH, Park SW, Harris TB, Kritchevsky SB, Nevitt M, Schwartz AV, Simonsick EM, Tylavsky FA, Visser M, Newman AB. The loss of skeletal muscle strength, mass, and quality in older adults: the health, aging and body composition study. J Gerontol A Biol Sci Med Sci. 2006; 61: 1059-64.

32. Janssen I, Heymsfield SB, Ross R. Low relative skeletal muscle mass (sarcopenia) in older persons is associated with functional impairment and physical disability. J Am Geriatr Soc. 2002; 50: 889-96.

33. Bonaldo P, Sandri M. Cellular and molecular mechanisms of muscle atrophy. Dis Model Mech. 2013; 6: 25-39.

34. Martinez PF, Okoshi K, Zornoff LA, Carvalho RF, Oliveira Junior SA, Lima AR, Campos DH, Damatto RL, Padovani CR, Nogueira CR, Dal Pai-Silva M, Okoshi MP. Chronic heart failure-induced skeletal muscle atrophy, necrosis, and myogenic regulatory factors changes. Med Sci Monit. 2010; 16: 374-83.

35. Lima ARR, Martinez PF, Damatto RL, Cezar MDM, Guizoni DM, Bonomo C, Oliveira SA Jr, Dal-Pai Silva M, Zornoff LA, Okoshi K, Okoshi MP. Heart failure-induced diaphragm myopathy. Cell Physiol Biochem. 2014; 34: 333-45.

36. Kortebein P, Ferrando A, Lombeida J, Wolfe R, Evans WJ. Effect of 10 days of bed rest on skeletal muscle in healthy older adults. JAMA. 2007; 297: 1772-4.

37. Kuh D, Bassey EJ, Butterworth S, Hardy R, Wadsworth ME, Team MS. Grip strength, postural control, and functional leg power in a representative cohort of British men and women: associations with physical activity, health status, and socioeconomic conditions. J Gerontol A Biol Sci Med Sci. 2005; 60: 224-31.

38. Morley JE. Hormones and the aging process. J Am Geriatr Soc. 2003; 51: S333-7.

39. Guillet $\mathrm{C}$, Boirie $Y$. Insulin resistance: a contributing factor to age-related muscle mass loss? Diabetes Metab. 2005; 31: 5S20-5S26.

40. Park SW, Goodpaster BH, Lee JS, Kuller LH, Boudreau R, de Rekeneire N, Harris TB, Kritchevsky S, Tylavsky FA, Nevitt M, Cho YW, Newman AB. Health Aging and Body Composition Study. Excessive loss of skeletal muscle mass in older adults with type 2 diabetes. Diabetes Care. 2009; 32: 1993-7.

41. Welle S, Brooks AI, Delehanty JM, Needler N, Thornton $\mathrm{CA}$. Gene expression profile of aging in human muscle. Physiol Genomics. 2003; 14: 149-59.
42. Chapman IM. The anorexia of aging. Clin Geriatr Med. 2007; 23: 735-56.

43. Campbell WW, Trappe TA, Wolfe RR, Evans WJ. The recommended dietary allowance for protein may not be adequate for older people to maintain skeletal muscle. J Gerontol A Biol Sci Med Sci. 2001; 56: M373-80.

44. Bodine SC, Stitt TN, Gonzalez M, Kline WO, Stover GL, Bauerlein R, Zlotchenko E, Scrimgeour A, Lawrence JC, Glass DJ, Yancopoulos GD. Akt/mTOR pathway is a crucial regulator of skeletal muscle hypertrophy and can prevent muscle atrophy in vivo. Nat Cell Biol. 2001; 3: 1014-19.

45. Sandri M. Signaling in muscle atrophy and hypertrophy. Physiology. 2008; 23: 160-70.

46. Bhasin S, Taylor WE, Singh R, Artaza J, Sinha-Hikim I, Jasuja R, Choi H, Gonzalez-Cadavid NF. The mechanisms of androgen effects on body composition: mesenchymal pluripotent cell as the target of androgen action. J Gerontol A Biol Sci Med Sci. 2003; 58: M1103-10.

47. Husmann I, Soulet L, Gautron J, Martelly I, Barritault D. Growth factors in skeletal muscle regeneration. Cytokine Growth Factor Rev. 1996; 7: 249-58.

48. Cassano M, Quattrocelli M, Crippa S, Perini I, Ronzoni F, Sampaolesi M. Cellular mechanisms and local progenitor activation to regulate skeletal muscle mass. J Muscle Res Cell Motil. 2009; 30: 243-53.

49. Sacheck JM, Ohtsuka A, McLary SC, Goldberg AL. IGF-I stimulates muscle growth by suppressing protein breakdown and expression of atrophy-related ubiquitin ligases, atrogin-1 and MuRF1. Am J Physiol Endocrinol Metab. 2004; 287: E591-601.

50. Bowen TS, Schuler G, Adams V. Skeletal muscle wasting in cachexia and sarcopenia: molecular pathophysiology and impact of exercise training. J Cachexia Sarcopenia Muscle. 2015; 6: 197-207.

51. Garcia-Prat L, Martinez-Vicente M, Muñoz-Canoves P. Autophagy: a decisive process for stemness. Oncotarget. 2016; 7: 12286-8. doi: 10.18632/oncotarget.7766.

52. Mangner N, Matsuo Y, Schuler G, Adams V. Cachexia in chronic heart failure: endocrine determinants and treatment perspectives. Endocrine. 2013; 43: 253-65.

53. Yoshida T, Tabony AM, Galvez S, Mitch WE, Higashi Y, Sukhanov S, Delafontaine P. Molecular mechanisms and signaling pathways of angiotensin II-induced muscle wasting: potential therapeutic targets for cardiac cachexia. Int J Biochem Cell Biol. 2013; 45: 2322-32.

54. Cunha TF, Bacurau AV, Moreira JB, Paixão NA, Campos JC, Ferreira JC, Leal ML, Negrão CE, Moriscot AS, Wisløff U, Brum PC. Exercise training prevents oxidative stress and ubiquitin-proteasome system overactivity and reverse skeletal muscle atrophy in heart failure. PLoS ONE. 2012; 7: e41701.

55. Okoshi MP, Romeiro FG, Paiva AS, Okoshi K. Caquexia associada à insuficiência cardíaca. Arq Bras Cardiol. 2013; 
100: 476-82.

56. Carter HN, Chen CC, Hood DA. Mitochondria, muscle health, and exercise with advancing age. Physiology. 2015; 30: 208-223.

57. Fan Y, Li Z, Han S, Lv C, Zhang B. The influence of gait speed on the stability of walking among the elderly. Gait Posture. 2016; 47: 31-6.

58. Fry CS, Lee JD, Mula J, Kirby TJ, Jackson JR, Liu F, Yang L, Mendias CL, Dupont-Versteegden EE, McCarthy JJ, Peterson CA. Inducible depletion of satellite cells in adult, sedentary mice impairs muscle regenerative capacity without affecting sarcopenia. Nat Med. 2015; 21: 76-80.

59. Lima AR, Martinez PF, Okoshi K, Guizoni DM, Zornoff LA, Campos DH, Oliveira SA Jr, Bonomo C, Pai-Silva MD, Okoshi MP. Myostatin and follistatin expression in skeletal muscles of rats with chronic heart failure. Int J Exp Path. 2010; 91: 54-62.

60. Damatto RL, Martinez PF, Lima AR, Cezar MD, Campos DH, Oliveira Junior SA, Guizoni DM, Bonomo C, Nakatani BT, Dal Pai Silva M, Carvalho RF, Okoshi K, Okoshi MP. Heart failure-induced skeletal myopathy in spontaneously hypertensive rats. Int J Cardiol. 2013; 167: 698-703.

61. Damatto RL, Lima AR, Martinez PF, Cezar MD, Okoshi K, Okoshi MP. Myocardial myostatin in spontaneously hypertensive rats with heart failure. Int J Cardiol. 2016; 215: 384-7.

62. Kang C, Chung E, Diffee G, Ji LL. Exercise training attenuates aging-associated mitochondrial dysfunction in rat skeletal muscle: role of PGC-1 $\alpha$. Exp Gerontol. 2013; 48: $1343-50$.

63. Calvani R, Joseph AM, Adhihetty PJ, Miccheli A, Bossola M, Leeuwenburgh C, Bernabei R, Marzetti E. Mitochondrial pathways in sarcopenia of aging and disuse muscle atrophy. Biol Chem. 2013; 394: 393-414.

64. Gouspillou G, Bourdel-Marchasson I, Rouland R, Calmettes G, Biran M, Deschodt-Arsac V, Miraux S, Thiaudiere E, Pasdois P, Detaille D, Franconi JM, Babot M, Trézéguet V, et al. Mitochondrial energetics is impaired in vivo in aged skeletal muscle. Aging Cell. 2014; 13: 39-48.

65. Wawrzyniak NR, Joseph AM, Levin DG, Gundermann DM, Leeuwenburgh C, Sandesara B, Manini TM, Adhihetty PJ. Idiopathic chronic fatigue in older adults is linked to impaired mitochondrial content and biogenesissignaling in skeletal muscle. Oncotarget. 2016; 7: 52695-709. doi: 10.18632/oncotarget.10685.

66. Leduc-Gaudet JP, Picard M, St-Jean Pelletier F, Sgarioto N, Auger MJ, Vallée J, Robitaille R, St-Pierre DH, Gouspillou G. Mitochondrial morphology is altered in atrophied skeletal muscle of aged mice. Oncotarget. 2015; 6: 17923 37. doi: 10.18632/oncotarget.4235.

67. Wenz T, Rossi SG, Rotundo RL, Spiegelman BM, Moraes CT. Increased muscle PGC-1alpha expression protects from sarcopenia and metabolic disease during aging. Proc Natl Acad Sci USA. 2009; 106: 20405-10.
68. Pietrangelo L, D’Incecco A, Ainbinder A, Michelucci A, Kern H, Dirksen RT, Boncompagni S, Protasi F. Agedependent uncoupling of mitochondria from $\mathrm{Ca}_{2}{ }^{+}$release units in skeletal muscle. Oncotarget. 2015; 6: 35358-71. doi: 10.18632/oncotarget.6139.

69. Stugiewicz M, Tkaczyszyn M, Kasztura M, Banasiak W, Ponikowski P, Jankowska EA. The influence of iron deficiency on the functioning of skeletal muscles: experimental evidence and clinical implications. Eur J Heart Fail. 2016; 18: 762-73.

70. Altenhofer S, Radermacher KA, Kleikers PW, Wingler K, Schmidt HH. Evolution of NADPH oxidase inhibitors: selectivity and mechanisms for target engagement. Antioxid Redox Signal. 2015; 23: 406-27.

71. Bouzid MA, Filaire E, McCall A, Fabre C. Radical oxygen species, exercise and aging: an update. Sports Med. 2015; 45: 1245-61.

72. Martinez PF, Bonomo C, Guizoni DM, Junior SA, Damatto RL, Cezar MD, Lima AR, Pagan LU, Seiva FR, Fernandes DC, Laurindo FR, Novelli EL, Matsubara LS, et al. Influence of $\mathrm{N}$ - acetylcysteine on oxidative stress in slow-twitch soleus muscle of heart failure rats. Cell Physiol Biochem. 2015; 35: 148-59.

73. Martinez PF, Bonomo C, Guizoni DM, Junior SA, Damatto RL, Cezar MD, Lima AR, Pagan LU, Seiva FR, Bueno RT, Fernandes DC, Laurindo FR, Zornoff LA, et al. Modulation of MAPK and NF-kB signaling pathways by antioxidant therapy in skeletal muscle of heart failure rats. Cell Physiol Biochem. 2016; 39: 371-84.

74. Ferreira LF, Laitano O. Regulation of NADPH oxidases in skeletal muscle. Free Radic Biol Med. 2016; 98: 18-28.

75. Choi MH, Ow JR, Yang ND, Taneja R. Oxidative stressmediated skeletal muscle degeneration: molecules, mechanisms, and therapies. Oxid Med Cell Longev. 2016; 2016: 6842568 .

76. Franzke B, Halper B, Hofmann M, Oesen S, Jandrasits W, Baierl A, Tosevska A, Strasser EM, Wessner B, Wagner KH. Group Vienna Active Ageing Study. The impact of six months strength training, nutritional supplementation or cognitive training on DNA damage in institutionalised elderly. Mutagenesis. 2015; 30: 147-53.

77. Harman D. Aging: a theory based on free radical and radiation chemistry. J Gerontol. 1956; 11: 298-300.

78. Tanhauser SM, Laipis PJ. Multiple deletions are detectable in mitochondrial DNA of aging mice. J Biol Chem. 1995; 270: 24769-75.

79. Bua E, Johnson J, Herbst A, Delong B, McKenzie D, Salamat S, Aiken JM. Mitochondrial DNA-deletion mutations accumulate intracellularly to detrimental levels in aged human skeletal muscle fibers. Am J Hum Genet. 2006; 79: 469-80.

80. Cadenas E, Davies KJ. Mitochondrial free radical generation, oxidative stress, and aging. Free Radic Biol Med. 2000; 29: 222-30. 
81. Fulle S, Protasi F, Di Tano G, Pietrangelo T, Beltramin A, Boncompagni S, Vecchiet L, Fanò G. The contribution of reactive oxygen species to sarcopenia and muscle ageing. Exp Gerontol. 2004; 39: 17-24.

82. Lexell J, Taylor CC, Sjöström M. What is the cause of the ageing atrophy? Total number, size and proportion of different fiber types studied in whole vastus lateralis muscle from 15- to 83-year-old men. J Neurol Sci. 1988; 84: 275 94.

83. Phillips T, Leeuwenburgh C. Muscle fiber specific apoptosis and TNF-alpha signaling in sarcopenia are attenuated by life-long calorie restriction. FASEB J. 2005; 19: 668-70.

84. Zhang H, Davies KJ, Forman HJ. Oxidative stress response and Nrf2 signaling in aging. Free Radic Biol Med. 2015; 88: 314-36.

85. Phu S, Boersma D, Duque G. Exercise and Sarcopenia. J Clin Densitom. 2015; 18: 488-92.

86. Konopka AR, Suer MK, Wolff CA, Harber MP. Markers of human skeletal muscle mitochondrial biogenesis and quality control: effects of age and aerobic exercise training. J Gerontol A Biol Sci Med Sci. 2014; 69: 371-8.

87. Guirado GN, Damatto RL, Matsubara BB, Roscani MG, Fusco DR, Cicchetto LA, Seki MM, Teixeira AS, Valle AP, Okoshi K, Okoshi MP. Combined exercise training in asymptomatic elderly with controlled hypertension: effects on functional capacity and cardiac diastolic function. Med Sci Monit. 2012; 18: CR461-5.

88. Pagan LU, Damatto RL, Cezar MD, Lima AR, Bonomo C, Campos DH, Gomes MJ, Martinez PF, Oliveira SA Jr, Gimenes R, Rosa CM, Guizoni DM, Moukbel YC, et al. Long-term low intensity physical exercise attenuates heart failure development in aging spontaneously hypertensive rats. Cell Physiol Biochem. 2015; 36: 61-74.

89. Guizoni DM, Oliveira-Junior SA, Noor SL, Pagan LU, Martinez PF, Lima AR, Gomes MJ, Damatto RL, Cezar MD, Bonomo C, Zornoff LA, Okoshi K, Okoshi MP. Effects of late exercise on cardiac remodeling and myocardial calcium handling proteins in rats with moderate and large size myocardial infarction. Int J Cardiol. 2016; 221: 406-12.

90. Atherton PJ, Smith K. Muscle protein synthesis in response to nutrition and exercise. J Physiol. 2012; 590: 1049-57.

91. Konopka AR, Douglass MD, Kaminsky LA, Jemiolo B, Trappe TA, Trappe S, Harber MP. Molecular adaptations to aerobic exercise training in skeletal muscle of older women. J Gerontol A Biol Sci Med Sci. 2010; 65: 1201-7.

92. Law TD, Clark LA, Clark BC. Resistance Exercise to Prevent and Manage Sarcopenia and Dynapenia. Annu Rev Gerontol Geriatr. 2016; 36: 205-28.

93. Davies KJ, Quintanilha AT, Brooks GA, Packer L. Free radicals and tissue damage produced by exercise. Biochem Biophys Res Commun. 1982; 107: 1198-205.

94. Radák Z, Pucsok J, Mecseki S, Csont T, Ferdinandy P. Muscle soreness-induced reduction in force generation is accompanied by increased nitric oxide content and DNA damage in human skeletal muscle. Free Radic Biol Med. 1999; 26: 1059-63.

95. Radák Z, Chung HY, Goto S. Exercise and hormesis: oxidative stress-related adaptation for successful aging. Biogerontology. 2005; 6: 71-5.

96. Radák Z, Apor P, Pucsok J, Berkes I, Ogonovszky H, Pavlik $\mathrm{G}$, Nakamoto H, Goto S. Marathon running alters the DNA base excision repair in human skeletal muscle. Life Sci. 2003; 72: 1627-33.

97. McArdle A, Jackson MJ. Exercise, oxidative stress and ageing. J Anat. 2000; 197: 539-41.

98. Florida-James GD, Simpson R, Davison G, Close G. Exercise, free radical metabolism, and aging: cellular and molecular processes. Oxid Med Cell Longev; 2016; 2016: 3813680

99. Jackson MJ. Reactive oxygen species in sarcopenia: Should we focus on excess oxidative damage or defective redox signalling? Mol Aspects Med. 2016; 50: 33-40.

100. de Gonzalo-Calvo D, Fernández-García B, de LuxánDelgado B, Rodríguez-González S, García-Macia M, Suárez FM, Solano JJ, Rodríguez-Colunga MJ, CotoMontes A. Chronic training increases blood oxidative damage but promotes health in elderly men. Age. 2013; 35 : 407-17.

101. Ristow M, Zarse K, Oberbach A, Klöting N, Birringer M, Kiehntopf M, Stumvoll M, Kahn CR, Blüher M. Antioxidants prevent health-promoting effects of physical exercise in humans. Proc Natl Acad Sci USA. 2009; 106: 8665-70.

102. Laforest S, St-Pierre DM, Cyr J, Gayton D. Effects of age and regular exercise on muscle strength and endurance. Eur J Appl Physiol Occup Physiol. 1990; 60: 104-11.

103. Takahashi M, Miyashita M, Kawanishi N, Park JH, Hayashida H, Kim HS, Nakamura Y, Sakamoto S, Suzuki $\mathrm{K}$. Low-volume exercise training attenuates oxidative stress and neutrophils activation in older adults. Eur J Appl Physiol. 2013; 113: 1117-26.

104. Fatouros IG, Jamurtas AZ, Villiotou V, Pouliopoulou S, Fotinakis P, Taxildaris K, Deliconstantinos G. Oxidative stress responses in older men during endurance training and detraining. Med Sci Sports Exerc. 2004; 36: 2065-72.

105. Gomes MJ, Martinez PF, Campos DH, Pagan LU, Bonomo C, Lima AR, Damatto RL, Cezar MD, Damatto FC, Rosa CM, Garcia CM, Reyes DR, Fernandes AA, et al. Beneficial effects of physical exercise on functional capacity and skeletal muscle oxidative stress in rats with aortic stenosisinduced heart failure. Oxid Med Cell Longev. 2016; 2016: 8695716 .

106. Gimenes C, Gimenes R, Rosa CM, Xavier NP, Campos DH, Fernandes AA, Cezar MD, Guirado GN, Cicogna AC, Takamoto AH, Okoshi MP, Okoshi K. Low intensity physical exercise attenuates cardiac remodeling and myocardial oxidative stress and dysfunction in diabetic rats. 
J Diabetes Res. 2015; 2015: 457848.

107. Cobley JN, Sakellariou GK, Owens DJ, Murray S, Waldron S, Gregson W, Fraser WD, Burniston JG, Iwanejko LA, McArdle A, Morton JP, Jackson MJ, Close GL. Lifelong training preserves some redox-regulated adaptive responses after an acute exercise stimulus in aged human skeletal muscle. Free Radic Biol Med 2014; 70: 23-32.

108. Sakellariou GK, Davis CS, Shi Y, Ivannikov MV, Zhang Y, Vasilaki A, Macleod GT, Richardson A, Van Remmen H, Jackson MJ, McArdle A, Brooks SV. Neuron-specific expression of $\mathrm{CuZnSOD}$ prevents the loss of muscle mass and function that occurs in homozygous CuZnSODknockout mice. FASEB J. 2014; 28: 1666-81.

109. Sun Y, Cui D, Zhang Z, Zhang T, Shi J, Jin H, Ge Z, Ji L, Ding S. Attenuated oxidative stress following acute exhaustive swimming exercise was accompanied with modified gene expression profiles of apoptosis in the skeletal muscle of mice. Oxid Med Cell Longev. 2016; 2016: 8381242 .

110. Greiwe JS, Cheng B, Rubin DC, Yarasheski KE, Semenkovich CF. Resistance exercise decreases skeletal muscle tumor necrosis factor alpha in frail elderly humans. FASEB J. 2001; 15: 475-82.

111. Benavent-Caballer V, Rosado-Calatayud P, Segura-Ortí E, Amer-Cuenca JJ, Lisón JF. Effects of three different lowintensity exercise interventions on physical performance, muscle CSA and activities of daily living: a randomized controlled trial. Exp Gerontol. 2014; 58: 159-65.

112. Laoutaris ID, Adamopoulos S, Manginas A, Panagiotakos DB, Kallistratos MS, Doulaptsis C, Kouloubinis A, Voudris V, Pavlides G, Cokkinos DV, Dritsas A. Benefits of combined aerobic/resistance/inspiratory training in patients with chronic heart failure. A complete exercise model? A prospective randomised study. Int J Cardiol. 2013; 167: 1967-72.

113. Dideriksen K, Reitelseder S, Holm L. Influence of amino acids, dietary protein, and physical activity on muscle mass development in humans. Nutrients. 2013; 5: 852-76.

114. Ghosh S, Lertwattanarak R, Lefort N, Molina-Carrion M, Joya-Galeana J, Bowen BP, Garduno-Garcia Jde J, AbdulGhani M, Richardson A, DeFronzo RA, Mandarino L, Van Remmen H, Musi N. Reduction in reactive oxygen species production by mitochondria from elderly subjects with normal and impaired glucose tolerance. Diabetes. 2011; 60: 2051-60.

115. Johnson ML, Irving BA, Lanza IR, Vendelbo MH, Konopka AR, Robinson MM, Henderson GC, Klaus KA, Morse DM, Heppelmann C, Bergen HR 3rd, Dasari S, Schimke JM, et al. Differential effect of endurance training on mitochondrial protein damage, degradation, and acetylation in the context of aging. J Gerontol A Biol Sci Med Sci. 2015; 70: 1386-93.

116. Powers SK, Criswell D, Lawler J, Ji LL, Martin D, Herb RA, Dudley G. Influence of exercise and fiber type on antioxidant enzyme activity in rat skeletal muscle. Am J Physiol. 1994; 266: R375-80.
117. Bouzid MA, Hammouda O, Matran R, Robin S, Fabre C. Influence of physical fitness on antioxidant activity and malondialdehyde level in healthy older adults. Appl Physiol Nutr Metab. 2015; 40: 582-9.

118. Wisloff U, Stoylen A, Loennechen JP, Bruvold M, Rognmo O, Haram PM, Tjønna AE, Helgerud J, Slørdahl SA, Lee SJ, Videm V, Bye A, Smith GL, et al. Superior cardiovascular effect of aerobic interval training versus moderate continuous training in heart failure patients. A randomized study. Circulation. 2007; 115: 3086-94.

119. Padilha CS, Ribeiro AS, Fleck SJ, Nascimento MA, Pina FL, Okino AM, Venturini D, Barbosa DS, Mayhew JL, Cyrino ES. Effect of resistance training with different frequencies and detraining on muscular strength and oxidative stress biomarkers in older women. Age. 2015; 37 : 104.

120. Bauer JM, Verlaan S, Bautmans I, Brandt K, Donini LM, Maggio M, McMurdo ME, Mets T, Seal C, Wijers SL, Ceda GP, De Vito G, Donders G, et al. Effects of a vitamin D and leucine-enriched whey protein nutritional supplement on measures of sarcopenia in older adults, the PROVIDE study: a randomized, double-blind, placebo-controlled trial. J Am Med Dir Assoc. 2015; 16: 740-7.

121. Anagnostis P, Dimopoulou C, Karras S, Lambrinoudaki I, Goulis DG. Sarcopenia in post-menopausal women: is there any role for vitamin D? Maturitas. 2015; 82: 56-64.

122. Lappe JM, Binkley N. Vitamin D and sarcopenia/falls. J Clin Densitom. 2015; 18: 478-82.

123. Pinto CL, Botelho PB, Carneiro JA, Mota JF. Impact of creatine supplementation in combination with resistance training on lean mass in the elderly. J Cachexia Sarcopenia Muscle. 2016; 7: 413-21.

124. Bosaeus I, Rothenberg E. Nutrition and physical activity for the prevention and treatment of age-related sarcopenia. Proc Nutr Soc. 2016; 75: 174-80.

125. Rizzoli R. Nutrition and sarcopenia. J Clin Densitom. 2015; 18: 483-7.

126. Suominen MH, Jyvakorpi SK, Pitkala KH, Finne-Soveri H, Hakala P, Mannisto S, Soini H, Sarlio-Lahteenkorva S. Nutritional guidelines for older people in Finland. J Nutr Health Aging. 2014; 18: 861-7.

127. Morley JE. Pharmacologic Options for the Treatment of Sarcopenia. Calcif Tissue Int. 2016; 98: 319-33.

128. Wendowski O, Redshaw Z, Mutungi G. Dihydrotestosterone treatment rescues the decline in protein synthesis as a result of sarcopenia in isolated mouse skeletal muscle fibres. J Cachexia Sarcopenia Muscle. 2016.

129. Borst SE, Yarrow JF. Injection of testosterone may be safer and more effective than transdermal administration for combating loss of muscle and bone in older men. Am J Physiol Endocrinol Metab. 2015; 308: E1035-42.

130. Santos DP, Okoshi K, Moreira VO, Seiva FR, Almeida FL, Padovani CR, Carvalho RF, Okoshi MP, Cicogna AC, Castro AV, Pai-Silva MD. Growth hormone attenuates 
skeletal muscle changes in experimental chronic heart failure. Growth Horm IGF Res. 2010; 20: 149-55.

131. Seiva FR, Ebaid GM, Castro AV, Okoshi K, Nascimento A, Rocha KK, Padovani CR, Cicogna AC, Novelli EL. Growth hormone and heart failure: oxidative stress and energetic metabolism in rats. Growth Horm IGF Res. 2008; 18: 27583.

132. Giannoulis MG, Martin FC, Nair KS, Umpleby AM, Sonksen P. Hormone replacement therapy and physical function in healthy older men. Time to talk hormones? Endocr Rev. 2012; 33: 314-77.

133. Camporez JP, Petersen MC, Abudukadier A, Moreira GV, Jurczak MJ, Friedman G, Haqq CM, Petersen KF, Shulman GI. Anti-myostatin antibody increases muscle mass and strength and improves insulin sensitivity in old mice. Proc Natl Acad Sci USA. 2016; 113: 2212-17.

134. Becker C, Lord SR, Studenski SA, Warden SJ, Fielding RA, Recknor CP, Hochberg MC, Ferrari SL, Blain H, Binder EF, Rolland Y, Poiraudeau S, Benson CT, et al. Steady Group. Myostatin antibody (LY2495655) in older weak fallers: a proof-of-concept, randomised, phase 2 trial. Lancet Diabetes Endocrinol. 2015; 3: 948-57.

135. Ferraro E, Giammarioli AM, Caldarola S, Lista P, Feraco A, Tinari A, Salvatore AM, Malorni W, Berghella L, Rosano G. The metabolic modulator trimetazidine triggers autophagy and counteracts stress-induced atrophy in skeletal muscle myotubes. FEBS J. 2013; 280: 5094-108.

136. Ferraro E, Pin F, Gorini S, Pontecorvo L, Ferri A, Mollace V, Costelli P, Rosano G. Improvement of skeletal muscle performance in ageing by the metabolic modulator trimetazidine. J Cachexia Sarcopenia Muscle. 2016; 7: 44957.

137. Javadov S, Jang S, Rodriguez-Reyes N, Rodriguez-Zayas AE, Soto Hernandez J, Krainz T, Wipf P, Frontera W. Mitochondria-targeted antioxidant preserves contractile properties and mitochondrial function of skeletal muscle in aged rats. Oncotarget. 2015; 6: 39469-81. doi: 10.18632/ oncotarget.5783.
138. Mavros Y, O’Neill E, Connerty M, Bean JF, Broe K, Kiel DP, Maclean D, Taylor A, Fielding RA, Singh MA. Oxandrolone augmentation of resistance training in older women: a randomized trial. Med Sci Sports Exerc. 2015; 47: 2257-67.

139. Toma RL, Vassão PG, Assis L, Antunes HK, Renno AC. Low level laser therapy associated with a strength training program on muscle performance in elderly women: a randomized double blind control study. Lasers Med Sci. 2016; 31: 1219-29.

140. Zdzieblik D, Oesser S, Baumstark MW, Gollhofer A, König D. Collagen peptide supplementation in combination with resistance training improves body composition and increases muscle strength in elderly sarcopenic men: a randomised controlled trial. Br J Nutr. 2015; 114: 1237-45.

141. Moresi V, Williams AH, Meadows E, Flynn JM, Potthoff MJ, McAnally J, Shelton JM, Backs J, Klein WH, Richardson JA, Bassel-Duby R, Olson EN. Myogenin and class II HDACs control neurogenic muscle atrophy by inducing E3 ubiquitin ligases. Cell. 2010; 143: 35-45.

142. Walsh ME, Bhattacharya A, Sataranatarajan K, Qaisar R, Sloane L, Rahman MM, Kinter M, Van Remmen H. The histone deacetylase inhibitor butyrate improves metabolism and reduces muscle atrophy during aging. Aging Cell. 2015; 14: 957-70.

143. Roberts HC, Dodds R, Sayer AA. Current clinical care of older adults with sarcopenia. J Clin Densitom. 2015; 18: 493-8. 